\title{
NAPNAP Position Statement on Immunizations
}

\author{
Lacey Eden
}

Cheryl Cairns

Karlen E. (Beth) Luthy

Brigham Young University - Provo, beth_luthy@byu.edu

Mary Koslap-Petraco

Follow this and additional works at: https://scholarsarchive.byu.edu/facpub

Part of the Other Nursing Commons, and the Pediatric Nursing Commons

\section{Original Publication Citation}

Eden, L., Cairns, C., Luthy, K. E., \& Koslap-Petraco, M. B. (2018). NAPNAP position statement on immunizations. Journal of Pediatric Health Care, 32(6), A9-A11.

\section{BYU ScholarsArchive Citation}

Eden, Lacey; Cairns, Cheryl; Luthy, Karlen E. (Beth); and Koslap-Petraco, Mary, "NAPNAP Position Statement on Immunizations" (2018). Faculty Publications. 5248.

https://scholarsarchive.byu.edu/facpub/5248 


\title{
NAPNAP Position
}

\section{Statement on Immunizations}

\author{
National Association of Pediatric Nurse Practitioners, Immunization Special \\ Interest Group, Lacey Eden, MS, NP-C, Cheryl Cairns, DNP, CPNP, RN, \\ Karlen E. Luthy, DNP, FNP-C, FAAN, FAANP, \& \\ Mary Koslap-Petraco, DNP, PPCNP-BC, CPNP, FAANP
}

The National Association of Pediatric Nurse Practitioners (NAPNAP) supports the timely and complete immunization of all infants, children, adolescents, and adults in an attempt to maximize the health and wellbeing of all people. Routine childhood immunizations prevent as many as 3 million deaths per year. In addition, 1.5 million deaths per year could be avoided if global vaccination efforts continue to improve (World Health Organization, 2017).

During the past two decades, immunization exemptions have steadily risen until the 2012-2013 school year, when the rate of immunization exemptions plateaued. Still, immunization exemptions corrode community immunity provided by population-based vaccination programs, and this warrants careful and continued monitoring to prevent vaccinepreventable disease outbreaks in the United States (Omer, Porter, Allen, Salmon, \& Bednarczyk, 2018).

The Centers for Disease Control and Prevention (CDC) Committee on Infectious Diseases and the Advisory Committee on Immunization Practices annually review and recommend routine vaccination to prevent 17 vaccinepreventable diseases (CDC, 2015, 2018b). In concert with the American Academy of Pediatrics, NAPNAP recognizes the importance of timely vaccinations for children and strongly encourages parents to adhere to the recommended

Adopted by the National Association of Pediatric Nurse Practitioners' Executive Board on June 9, 2018. This document replaces the 2015 NAPNAP Position Statement on Immunizations.

All priority position statements from the National Association of Pediatric Nurse Practitioners automatically expire 3 years after publication unless reaffirmed, revised, or retired at or before that time.

Correspondence: NAPNAP National Office, 5 Hanover Square, Suite 1401, New York, NY 10004.

J Pediatr Health Care. (2018) 32, A9-A11

$0891-5245 / \$ 36.00$

Copyright $(2) 2018$ by the National Association of Pediatric Nurse Practitioners. Published by Elsevier Inc. All rights reserved.

https://doi.org/10.1016/j.pedhc.2018.07.002 immunization schedule as the best way to protect their children and community from vaccine-preventable infectious diseases (American Academy of Pediatrics, 2018).

NAPNAP considers nurse practitioners (NPs) to be in the best position to inform parents of the scientific and evidence-based foundation of the current immunization recommendations. This education must include the most current scientific evidence related to vaccine safety, risk, and benefits. Parents should know how to find the most current, correct, and evidence-based resources. Conversely, they must be informed about sources and dangers of misinformation. Using a nonjudgmental approach, NPs are compelled to inform parents about the risks of not vaccinating their children as recommended by the evidence.

NAPNAP expects NPs to be skillful clinicians and encourages NPs to become identified as leaders in the health and safety of children and families. NPs must remain knowledgeable about the ever-changing science of vaccination and recommendations for immunizations. Promoting vaccines should be done at the individual, local, state, national, and international levels. NPs are encouraged to participate on employer, hospital, school, local, state, and national committees that address immunization policies and practices, including advocating for increased funding for vaccines.

In an effort to ensure that all pediatric populations are protected against vaccine-preventable illness and remain healthy, NAPNAP affirms that NPs and other pediatric health care providers must do the following.

1. Ensure access to timely immunization for all children.

2. Avoid any and all missed opportunities to vaccinate.

3. Consider every health care encounter as a means to review immunization records, educate parents about immunization safety and efficacy, and vaccinate as needed.

4. Acknowledge the ultimate goal of immunizing children in a timely fashion is to maximize the health of each individual child. 
5. Encourage and enable parents and caregivers to critically evaluate vaccine information.

6. Recommend parents, caregivers, and other adults to remain compliant with recommended immunizations for their age and risk group in order to protect children in their care.

7. Distribute the evidence-based CDC Vaccine Information Statements (VISs) for each recommended vaccine to parents and caregivers at every immunization encounter (CDC, 2018a).

8. Ensure adherence to immunization schedules by utilizing electronic health records, statewide vaccine registries, and recall systems to promote continued development of these systems.

9. Remain knowledgeable via local or national immunization groups, educational programs or conferences, evidence-based research articles, and peer-reviewed journals.

10. Immediately incorporate changes in immunization policies, recommendations, and practices into daily practice (Kroger, Duchin, \& Vazquez, 2017).

11. Provide complete, accurate, and culturally sensitive educational programs about immunizations to the public, childcare centers, schools, and community groups, including information on benefits, safety, evidence-based quality resources, and the importance of active and timely participation in immunization programs.

12. Utilize news, social media, and other applicable communication methods to influence and direct the conversation regarding immunization safety, efficacy, and necessity.

13. Utilize quality improvement principles to evaluate immunization practices for the purpose of improving compliance with recommended immunization practices and educating members of the health care team.

14. Lead policy change in states to eliminate nonmedical exemptions for school entry.

15 Actively participate on local, state, and national committees, advisory groups, and other venues that impact policies concerning childhood immunization practices.

16. Support any local, state, or federal legislation that aims to keep childhood immunizations available, accessible, and affordable for all children regardless of social or economic status or the type of health insurance.

17. Serve as immunization expert on local, regional, or national committees to support the safety and efficacy of childhood immunization programs.

18 Advocate for an integrated national immunization infrastructure to ensure the supply and delivery of vaccines, maintenance of coverage rates, outbreak control, and immunization education (Groom et al., 2015).

19. Understand the responsibility to report adverse outcomes following any immunization to the Vaccine
Adverse Event Reporting System (VAERS; CDC, 2017) and the purpose of the Vaccine Injury Compensation Program (VICP; U.S. Department of Health and Human Services, Health Resources and Services Administration, 2018).

20. Keep informed of the incidence of vaccine-preventable diseases in your area and be proficient in the ability to diagnose the illness.

21. In the event of vaccine-preventable disease diagnosis, encourage parents to keep children with vaccine-preventable disease at home from school and out of public settings for the duration of the outbreak as recommended by state and national guidelines (Aronson \& Shope, 2016).

In summary, NAPNAP is an organization whose mission is to empower pediatric nurse practitioners, pediatricfocused advanced practice registered nurses, and their interprofessional partners to enhance child and family health through leadership, advocacy, professional practice, education, and research and is committed to the health and wellbeing of all children and their families. NAPNAP recognizes the immense benefits of immunizations for children and the community alike. NAPNAP encourages NPs, as well as other pediatric health care providers, to consistently assess patient immunization status, limit missed opportunities to vaccinate, support immunization programs, and promote community awareness of the value of immunization of all children. NPs are compelled to be informed clinicians, skilled communicators, strong leaders, advocates, and champions for evidence-based immunization programs. It is the position of NAPNAP that NPs and elected leaders at the local, state, and federal levels support legislative efforts to appropriate funds for comprehensive immunization delivery, for a national immunization registry, and to maintain the VAERS and VICP programs.

The National Association of Pediatric Nurse Practitioners would like to acknowledge the following members from the Immunization Special Interest Group (SIG) for their contribution to this statement: Lacey Eden, MS, NP-C; Cheryl Cairns, DNP, CPNP, RN, APN; Karlen E. Lutby, DNP, FNP-C, FAAN, FAANP; and Mary Koslap-Petraco, DNP, PPCNP-BC, CPNP, FAANP.

\section{REFERENCES}

American Academy of Pediatrics. (2018). Immunization schedules for 2018. Itasca, IL: Author. Retrieved from https://redbook. solutions.aap.org/SS/Immunization_Schedules.aspxcdc

Aronson, S. S., \& Shope, T. R. (2016). Managing infectious disease in child care and schools (4th ed.) Elk Grove Village, IL: American Academy of Pediatrics. Retrieved from http://ebooks.aap publications.org/content/managing-infectious-diseases-inchild-care-and-schools-4th-ed

Centers for Disease Control and Prevention. (2015). Epidemiology and prevention of vaccine-preventable diseases. Atlanta, GA: Author. Retrieved from https://www.cdc.gov/vaccines/pubs/ pinkbook/genrec.html 
Centers for Disease Control and Prevention. (2017). Vaccine adverse event reporting system (NAERS). Atlanta, GA: Author. Retrieved from https://www.cdc.gov/vaccinesafety/ensuringsafety/moni toring/vaers/index.html

Centers for Disease Control and Prevention. (2018a). Instructions for using Vaccine Information Statements. Atlanta, GA: Author. Retrieved from https://www.colc.gov/vaccines/schedules/hcp/adult.html

Centers for Disease Prevention and Control. (2018b). Recommended immunization schedule for children and adolescents aged 18 years or younger, United States, 2018. Atlanta, GA: Author. Retrieved from https://www.cdc.gov/ vaccines/schedules/hcp/child-adolescent.html

Groom, H., Hopkins, D. P., Pabst, L. J., Morgan, J. M., Patel, M., Calonge, N., ... Community Preventive Services Task Force. (2015). Immunization information systems to increase vaccination rates: A community guide systematic review. Journal of Public Health Management and Practice, 21, 227-248.
Kroger, A. T., Duchin, J., \& Vázquez, M. (2017). General best practice guidelines for immunizations. Best practice guidelines for immunization of the Advisory Committee for Immunization Practice (ACIP). Atlanta, GA: Centers for Disease Control and Prevention. Retrieved from www.cdc.gov/vaccines/hcp/aciprecs/general-recs/downloads/general-recs.pdf

Omer, S. B., Porter, R. M., Allen, K., Salmon, D. A., \& Bednarczyk, R. B. (2018). Trends in Kindergarten rates of vaccine exemption and state-level policy, 2011-2016. Open Forum Infectious Diseases, 5(2), 1-6.

U.S. Department of Health and Humans Services, Health Resources and Services Administration. (2018). National vaccine injury compensation program. Rockville, MD: Author. Retrieved from https://www. hrsa.gov/vaccine-compensation/index.html

World Health Organization. (2017). Immunization coverage. Geneva, Switzerland: Author. Retrieved from http://www.who.int/media centre/factsheets/fs378/en/

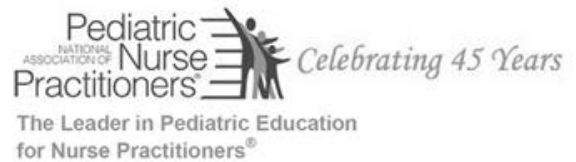

\section{SPECIALTY SYMPOSIA}

\section{Bringing highly rated, evidence-based CE to \\ PNPs, FNPs and other pediatric providers. \\ Whether you want to expand your knowledge or meet licensure requirements, we look forward to welcoming you to these great cities.}

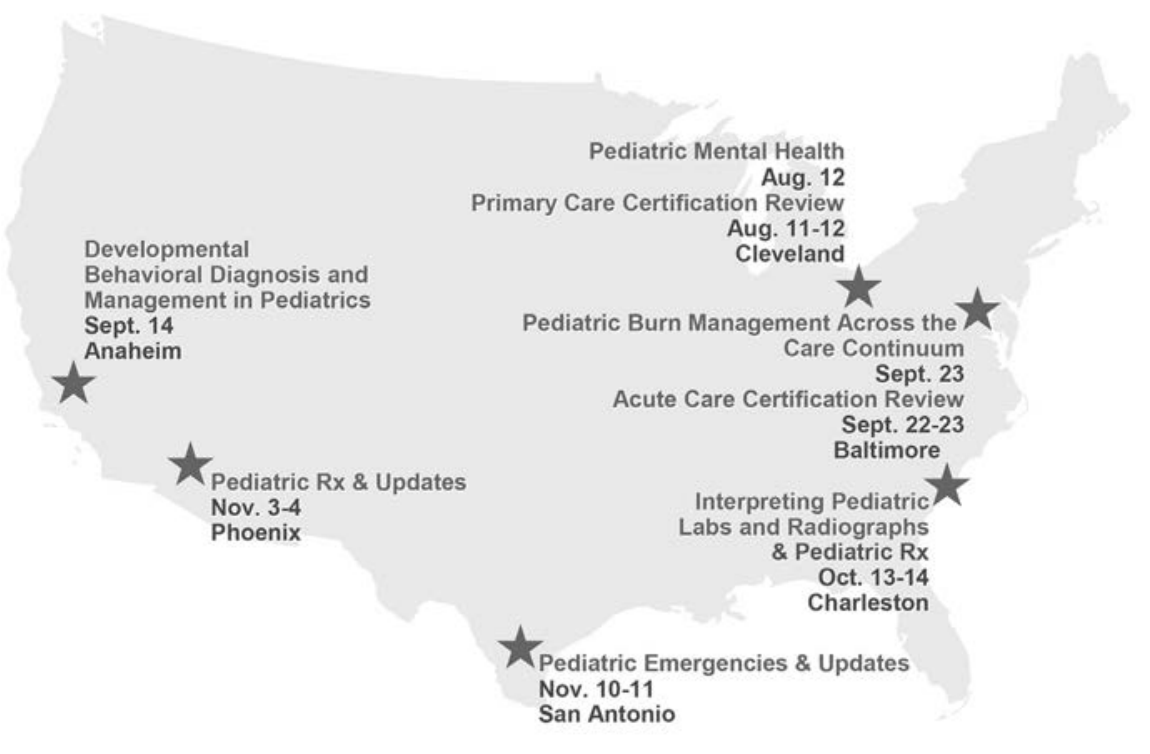

All symposia offer at least 7.0 contact hours! Visit napnap.org/symposia to get details. 